\title{
A systematic review and meta-analysis of vertical transmission route of HIV in Ethiopia
}

\author{
Aklilu Endalamaw ${ }^{1 *}$, Amare Demsie $^{1}$, Setegn Eshetie ${ }^{2}$ and Tesfa Dejenie Habtewold ${ }^{3,4}$
}

\begin{abstract}
Background: The burden of mother-to-child transmission rate of HIV is high and risk factors are common in Ethiopia. This systematic review and meta-analysis intended to provide the pooled estimation of mother-to-child transmission rate and its risk factors in Ethiopia.

Methods: We searched PubMed, Google Scholar, EMBASE and Web of Science electronic databases for all available references. We included observational studies including case-control, cohort, and cross-sectional studies. The search was further limited to studies conducted in Ethiopia and publish in English. Heterogeneity was checked using the $I^{2}$ statistic. Egger's test and the funnel plot were used to assess publication bias. A meta-analysis using a weighted inverse variance random-effects model was performed.
\end{abstract}

Results: A total of 18 studies with 6253 individuals were included in this systematic review and meta-analysis. Of these, 14 studies with 4624 individuals were used to estimate the prevalence. The estimated pooled prevalence of mother-tochild transmission of HIV was $11.4 \%(95 \% \mathrm{Cl}=9.1-13.7)$. The pooled adjusted odds ratio (AOR) of mother-to-child transmission of HIV for the infants from rural area was $3.8(95 \% \mathrm{Cl}=1.4$ to 6.3$)$, infants delivered at home was $3.2(95 \% \mathrm{Cl}=1.2$ to 5.2$)$, infant didn't take antiretroviral prophylaxis was $5.8(95 \% \mathrm{Cl}=1.5$ to 10.3$)$, mother didn't take antiretroviral prophylaxis was $6.1(95 \% \mathrm{Cl}=2.5$ to 9.6), mothers didn't receive PMTCT intervention was $5.1(95 \% \mathrm{Cl}=1.6,8.6)$, and on mixed feeding was $4.3(95 \% \mathrm{Cl}=1.8$ to 6.7$)$.

Conclusions: This systematic review and meta-analysis showed that mother-to-child transmission rate of HIV was high in Ethiopia. Being from the rural residence, home delivery, not taking antiretroviral prophylaxis, the absence of PMTCT intervention, and mixed infant feeding practices increased the risk of HIV transmission.

Trial registration: It is registered in the Prospero database: (PROSPERO 2017: CRD42017078232).

Keywords: HIV-exposed infants, HIV transmission, Infants, Meta-analysis, Mothers, Ethiopia

\section{Background}

The pandemics of Human Immunodeficiency Virus (HIV) have been affecting many segments of the population all over the world [1]. In 2016, around 36.7 million people lived with HIV [2]. In sub-Saharan Africa and globally, 110,000 and 160,000 children got new HIV infection respectively $[2,3]$.

HIV has many routes of transmission including mother-to-child transmission (MTCT) [4]. More than 90\%

\footnotetext{
* Correspondence: yaklilu12@gmail.com

${ }^{1}$ Department of Pediatrics and Child Health Nursing, School of Nursing,

College of Medicine and Health Sciences, University of Gondar, P.O.BOX: 196

Gondar, Ethiopia

Full list of author information is available at the end of the article
}

of children acquired HIV through MTCT [5, 6], predominantly high in Africa [7]. Studies reported that MTCT rate during pregnancy or postpartum period was $23 \%$ [8] even though it varies from 15 to $45 \%$ in the absence of prophylaxis [9]. Between 2009 and 2013, the MTCT rate reduced from 28 to $18 \%$ in sub-Saharan Africa [10].

To control MTCT of HIV as part of end Acquired Immunodeficiency Syndrome epidemic strategy [11, 12], several activities have been inaugurated in Ethiopia. Ethiopia implemented prevention of mother to child transmission (PMTCT) intervention since 2001 [13], such as increasing institutional delivery, Antiretroviral

(C) The Author(s). 2018 Open Access This article is distributed under the terms of the Creative Commons Attribution 4.0 International License (http://creativecommons.org/licenses/by/4.0/), which permits unrestricted use, distribution, and 
coverage, infant prophylaxis, and proper feeding practices of infants [14, 15].

However, in 2016, 40, 11, and 26\% of Ethiopian women ever screened for HIV, started mixed feeding for infants before 6 months and delivered at health institutions, respectively [16]. Consequently, MTCT of HIV occurred significantly. Similarly, there were an estimated 14,000 HIV-positive newborns in Ethiopia [17].

Despite many efforts to study the prevalence and risk factors of MTCT of HIV, there are still fragmented primary studies in Ethiopia [18-35]. The majority of the studies showed epidemiologic variations from $0.7 \%$ [28] to $32.0 \%$ [19] over time and across geographical areas. Similarly, a disagreement among those studies about major factors was observed. Therefore, this systematic review and meta-analysis aimed to provide a pooled national estimate of the prevalence of MTCT of HIV and its associated factors in Ethiopia. The result of this study may help to guide policy and decision makers in the prevention and control of MTCT of HIV.

\section{Methods \\ Reporting}

The Preferred Reporting Items for Systematic Reviews and Meta-analyses (PRISMA) guideline [36] was used to report the result of this systematic review and meta-analyses (Additional file 1).

\section{Databases and searching strategy}

We searched PubMed, Web of Science, Excerpta Medica Database (EMBASE), Google Scholar and psycEXTRA databases for all available studies using the following search terms: "HIV"; "human immunodeficiency virus"; "AIDS"; "Acquired immunodeficiency syndrome"; "mother to child"; "mother to infant"; "mother"; "infant"; "newborn"; "neonate"; "baby"; "child"; "vertical transmission"; "mother-to-child transmission"; "MTCT"; "transmission"; "PMTCT"; "prevention of mother to child transmission"; "factors"; "determinants"; "predictors"; "enablers"; "barriers"; and "Ethiopia". Search string was developed using "AND" and "OR" Boolean operators. An example of the search details for PubMed illustrated in Additional file 2. Grey literatures were also searched from Ethiopian's University (University of Gondar and Addis Ababa University) research repository online library. In addition, a manual search of the reference lists of included articles was performed.

\section{Inclusion and exclusion criteria}

The studies were included if they met the following inclusion criteria: (1) observational studies, including cross-sectional, case-control and cohort studies; (2) studies conducted in Ethiopia; (3) studies that reported prevalence and/or risk factors; (4) the outcome was mother-to-child HIV transmission; (4) both published and unpublished studies at any time; (5) studies used any HIV diagnosis approach. MTCT of HIV was defined as the proportion of the number of infants positive for HIV divided by the total HIV-exposed infants assessed. The prevalence in cohort studies the cumulative incidence was considered as prevalence, in which the number of new HIV infected cases divided by the overall sample size. Studies focused on the assessment of knowledge, attitude, and practice of MTCT without the outcome of interest of this study, program evaluation studies, studies with only abstracts, case studies, qualitative studies and citations without full-text were excluded.

\section{Study selection and quality assessment}

All retrieved studies were exported to Endnote version 7 (Thomson Reuters, London) reference manager and duplicated studies were carefully removed. Two investigators $(\mathrm{AE}$ and $\mathrm{AD})$ independently screened the titles and abstracts which were followed by a full-text review to determine the eligibility of each study. The disagreement was solved by consensus. Two independent reviewers ( $\mathrm{AE}$ and $\mathrm{SE}$ ) have assessed the quality of the studies. The quality of each article was evaluated using Joanna Briggs Institute (JBI) quality appraisal criteria adapted for studies reporting prevalence data, cross-sectional, cohort and case-control studies [37]. The following items were used to appraise cross-sectional studies: (1) inclusion criteria; (2) description of study subject and setting; (3) valid and reliable measurement of exposure; (4) objective and standard criteria used; (5) identification of confounder; (6) strategies to handle confounder; (7) outcome measurement; and (8) appropriate statistical analysis. The following items were used for appraising cohort studies: (1) similarity of groups; (2) similarity of exposure measurement; (3) validity and reliability of measurement; (4) identification of confounder; (5) strategies to deal with confounder; (6) appropriateness of groups/participants at the start of the study; validity and reliability of outcome measured; (8) sufficiency of follow up time; (9) completeness of follow-up or descriptions of reason to loss to follow-up; (10) strategies to address incomplete follow-up; and (11) appropriateness of statistical analysis. The following items were used for appraising case-control study: (1) comparable groups; (2) appropriateness of cases and controls; (3) criteria to identify cases and controls; (4) standard measurement of exposure; (5) similarity in measurement of exposure for cases and controls; (6) handling of confounder; (7) strategies to handle confounder; (8) standard assessment of outcome; (9) appropriateness of duration for exposure; and (10) appropriateness of statistical analysis. Studies considered low risk whenever fitted to $50 \%$ and or above quality assessment checklist criteria's. 


\section{Data extraction}

Two independent reviewers (AE and TD) extracted the data and cross-checked to ensure consistency. Discrepancies were solved by discussion and repeating the procedure. Information about the author and year of publication, study area, study design, sample size, the prevalence rate of MTCT of HIV and AOR for identified risk factors were extracted. The reviewer contacted the corresponding author(s) for further information whenever pertinent data were missed from the included studies.

\section{Data analysis}

A weighted inverse variance random-effects model [38] was used to estimate the overall pooled prevalence. The pooled AOR of rural residence, home delivery, mixed infant feeding, mothers ARV prophylaxis, PMTCT intervention, and infant ARV prophylaxis. Subgroup analyses according to the study geographical area and study design were employed to adjust the variations in the pooled estimate of the prevalence. The percentage of total variation across studies due to heterogeneity was assessed using an $\mathrm{I}^{2}$ statistic [39]. The values of $\mathrm{I}^{2} 25$, 50 , and $75 \%$ represented low, moderate and high heterogeneity respectively [39]. Publication bias across studies was checked using funnel plot and Egger's regression test [40]. STATA version 14 (Stata Corp, College Station, TX, USA) statistical software was used for all statistical analysis.

\section{Result}

\section{Characteristics of included studies}

The search strategy identified 1378 articles from PubMed, 78 articles from Google Scholar, 17 articles from psycEXTRA, 13 articles from EMBASE, 4 articles from Web of Science, 9 articles from Ethiopian's University research repository online library, and 7 articles through manual search. First, 65 articles were selected for full-text review after duplicated $(n=296)$ and irrelevant studies based on the titles and abstracts $(n=1146)$ were removed. Then, the full-text review was performed and 47 articles were excluded for different reasons. Finally, 18 articles were found relevant to determine the prevalence and/or associated factors. Fig. 1 has shown the study selection process.

Among eighteen studies, one case-control [30], seven cross-sectional [18-20, 24, 27, 29, 35], and ten cohort studies $[21-23,25,26,28,31-34]$ were found. Regarding the geographical area, five studies were conducted in Amhara region [20, 22-24, 27], five in Oromia [18, 21, 30, 32, 34], one in Southern Nation Nationalities and People (SNNPR) [26], six in Addis Ababa [19, 28, 29, 31, 33, 35] and one in Dire Dawa city [25]. Table 1 shows the characteristics of those studies.

\section{Quality of the included studies}

One study was assessed using JBI checklist for case-control studies [30], ten studies [21-23, 25, 26, 28, 31-34] using JBI checklist for cohort studies, and seven studies [18-20, 24, 27, 29, 35] using the JBI checklist for cross-sectional studies. None of the studies were excluded based on the quality assessment criteria (Table 1).

\section{Meta-analysis \\ Publication bias}

Three studies [26-28] were excluded from prevalence estimation after checking funnel plot and the significance of Egger's regression test. However, they were not excluded from meta-analysis for risk factors. Significant publication bias with an Egger's regression $p$-value $<0.001$ was seen when all studies considered (Fig. 2a). After adjustment, Egger's regression p-value was 0.206 , indicated a reduced publication bias (Fig. 2b).

\section{Qualitative description}

Primarily, among eighteen studies, the one was case-control study was not considered in the prevalence estimation. The other three studies [26-28] were excluded from the pooled analysis step-by-step until p-value in the Egger's regression test scored greater than 0.05 . These studies were: Girma M [28] report the prevalence of MTCT of HIV was $0.7 \%$ in Addis Ababa whereas Asmamaw et al. [27] reported 3.8\% in Amhara region. In addition, Tadele $\mathrm{T}$ et al. [26] found 4.16\% prevalence of MTCT of HIV in SNNPR region.

\section{Prevalence of MTCT of HIV}

Consequently, fourteen studies [18-25, 29, 31-35] were included in the final meta-analysis. The prevalence of MTCT of HIV ranges from 5.9\% in Amhara region [23] to 32.1\% in Addis Ababa [19]. The pooled prevalence was 11.4\% (95\% Confidence Interval) $\mathrm{CI}=9.1$ to $13.7, \mathrm{I}^{2}=8.43 \%$; $p<0.001$ ) (Fig. 3). Egger's regression test $p$-value $=0.206$.

We performed subgroup analysis by region and study design. Consequently, MTCT of HIV prevalence was $15.7 \%$ in Dire Dawa, $12.34 \%$ in Addis Ababa, 11.95\% in Oromia, and $9.56 \%$ in Amhara region (Fig. 4).

In addition, the higher prevalence was (13.3\%) reported among cohort studies. The detailed results are illustrated in Fig. 5.

\section{Risk factors for MTCT of HIV}

Based on the review done associated factors were categorized into three thematic areas. These were: (1) socio-demographic, (2) prenatal, intranatal and postnatal, and (3) clinical and drugs-related factors.

\section{Socio-demographic related factors}

Those children who were born from mothers age greater than 27 years were more likely $(\mathrm{AOR}=5.4,95 \% \mathrm{CI}=$ 


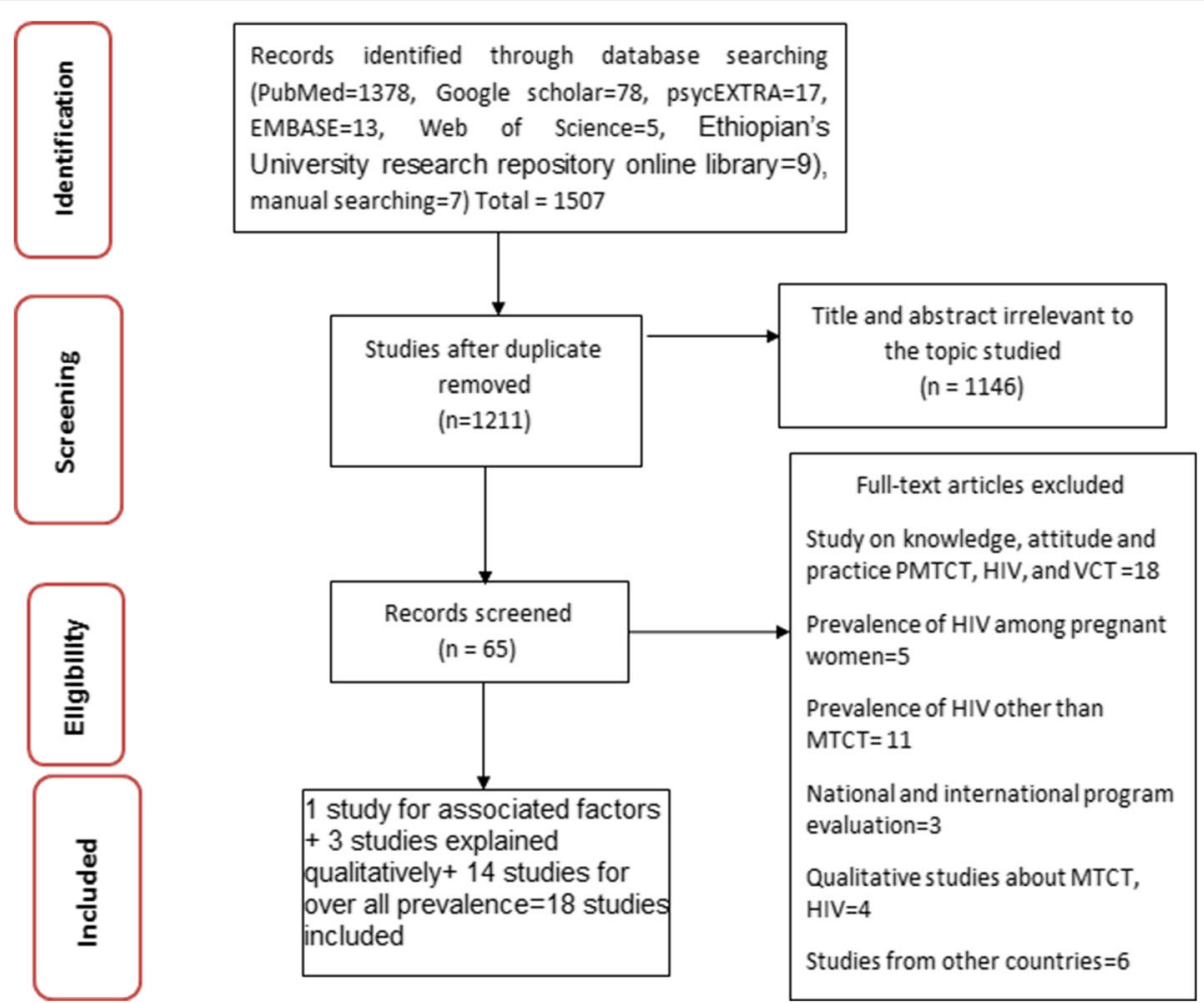

Fig. 1 Studies selection process flow chart for the studies included in the analyses

Table 1 General characteristics of the included studies

\begin{tabular}{|c|c|c|c|c|c|}
\hline Author/Year & Study Area & Study design & Sample size & Prevalence $(95 \% \mathrm{Cl})$ & Quality \\
\hline Moges AN et al./2017 [23] & Amhara & Retrospective cohort & 305 & $5.9(3.3-8.5)$ & Low risk \\
\hline Tadele T et al./2014 [26] & SNNP & Retrospective follow up & 457 & $4.2(2.3-6.0)$ & Low risk \\
\hline Amare H et al./2014 [19] & Addis Ababa & Cross-sectional & 159 & $32.1(24.8-39.4)$ & Low risk \\
\hline Berhan Z et al./2014 [20] & Amhara & Cross-sectional & 434 & $10.1(7.3-12.9)$ & Low risk \\
\hline Birlie B et al./2016 [21] & Oromia & Retrospective follow up & 146 & 17(10.9-23.1) & Low risk \\
\hline Koye DN, Zeleke BM/2013 [22] & Amhara & Retrospective follow up & 509 & 10(7.4-12.6) & Low risk \\
\hline Wudineh F, Damtew B/ 2016 [25] & Dire Dawa & Retrospective cohort & 382 & $15.7(12.1-19.3)$ & Low risk \\
\hline Abdula M/2015 [26] & Oromia & Cross-sectional & 130 & $7.7(3.1-12.3)$ & Low risk \\
\hline Asmamaw Y et al./2017 [27] & Amhara & Cross-sectional & 313 & $3.8(1.7-5.9)$ & Low risk \\
\hline Tigabu Z, Wasie B/2016 [24] & Amhara & Cross-sectional & 484 & $12.4(1.5-9.5)$ & Low risk \\
\hline Girma M/2016 [28] & Addis Ababa & Prospective cohort & 435 & $0.7(-0.08-1.5)$ & Low risk \\
\hline Shargie MB et al./2011 [29] & Addis Ababa & Cross-sectional & 118 & $6.8(2.3-11.3)$ & Low risk \\
\hline Burusie A, Deyessa N/2015 [30] & Oromia & Case-control & 424 & Not applicable & Low risk \\
\hline Mirkuzie AH et al./2010 [31] & Addis Abba & Retrospective cohort & 896 & $11.8(9,7-13.9)$ & Low risk \\
\hline Derebe G et al./2014 [32] & Oromia & Retrospective cohort & 426 & $9.6(6.8-12.4)$ & Low risk \\
\hline Mirkuzie AH et al./2011 [33] & Addis Ababa & Prospective cohort & 71 & $8.4(1.9-14.8)$ & Low risk \\
\hline Kumela K et al./2015 [34] & Oromia & Retrospective cohort & 180 & $15.5(10.2-20.8)$ & Low risk \\
\hline Negash TG, Ehlers VJ/2016 [35] & Addis Ababa & Cross-sectional & 384 & $6.0(3.6-11.3)$ & Low risk \\
\hline
\end{tabular}




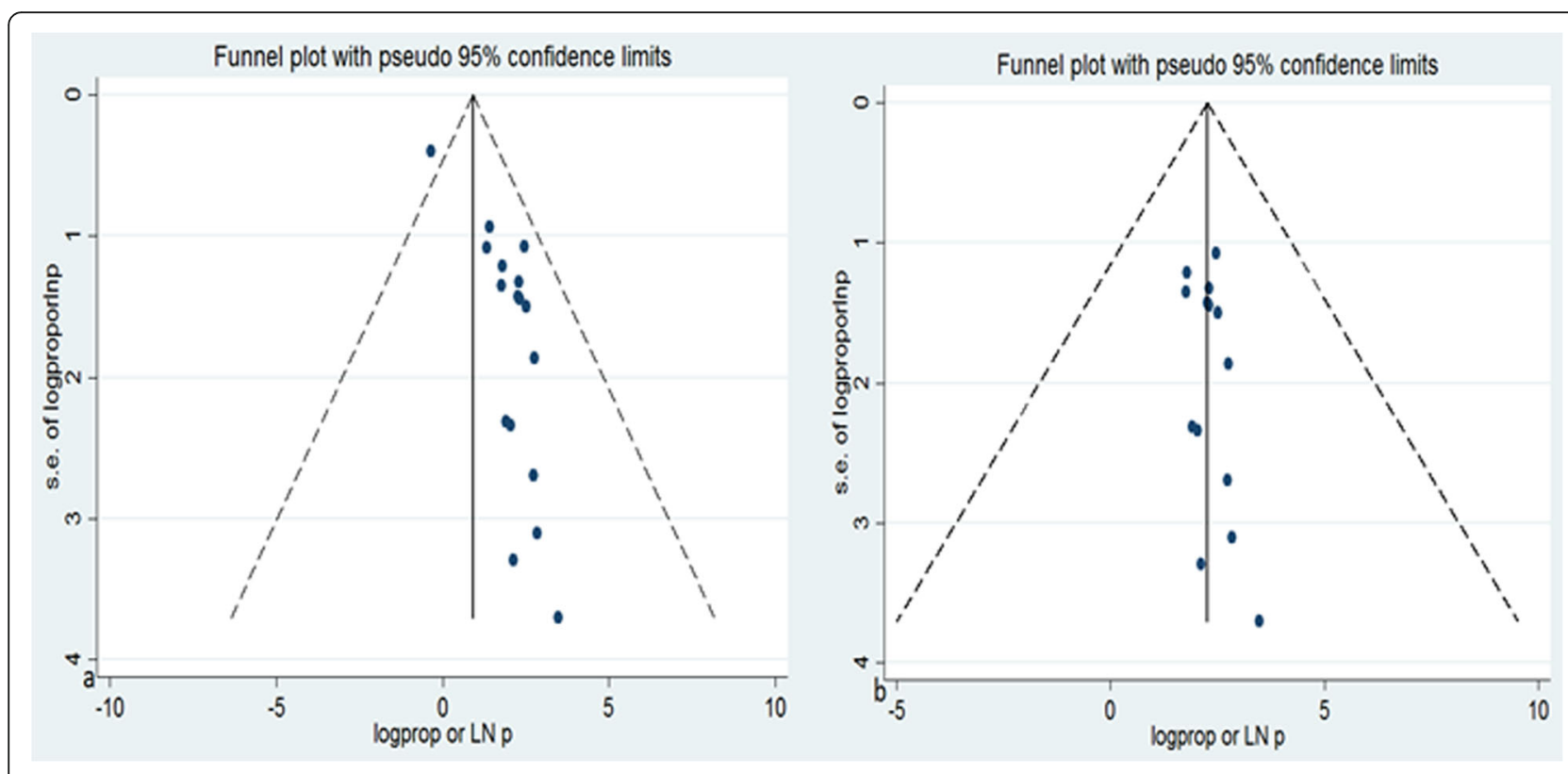

Fig. 2 Funnel plot before adjustment (a) and after adjustment (b) for publication bias, Logprop or LNP (log of proportion) represented in the x-axis and standard error of log proportion in the $y$-axis

$1.15,25.70)$ to acquire HIV infection as compared to those with less than 27 years [23]. Two studies [22, 25] reported being rural residence was associated factor of MTCT of HIV. The pooled AOR of MTCT of HIV in infant from rural versus urban residence was 3.8 (95\% $\mathrm{CI}=1.4$ to $\left.6.3, \mathrm{I}^{2}=0.0 \%, p=0.506\right)($ Fig. 6$)$.

\section{Prenatal, Intranatal, and post natal-related factors}

Mothers who became pregnant after they knew their HIV positivity ( $\mathrm{AOR}=0.22,95 \% \mathrm{CI}=0.049,096)$ were less likely to transmit HIV to their infants [23]. Additionally, the rate of HIV infection was higher among those mothers who knew their HIV sero-positivity

\begin{tabular}{|c|c|c|c|c|}
\hline Author & Year & & $\mathrm{P}(95 \% \mathrm{Cl})$ & $\begin{array}{l}\% \\
\text { Weight }\end{array}$ \\
\hline Moges AN et al. & 2017 & $=1$ & $5.90(3.26,8.54)$ & 8.16 \\
\hline Amare $\mathrm{H}$ et al. & 2014 & $\rightarrow$ & $32.10(24.84,39.36)$ & 4.80 \\
\hline Berhan $Z$ et al & 2014 & + & $10.10(7.27,12.93)$ & 8.03 \\
\hline Kumela K.et al & 2015 & $\rightarrow$ & $15.50(10.21,20.79)$ & 6.17 \\
\hline Birlie B et al. & 2016 & $\rightarrow$ & $17.00(10.91,23.09)$ & 5.58 \\
\hline Mirkuzie AH.et.al & 2011 & $\rightarrow$ & $8.40(1.95,14.85)$ & 5.33 \\
\hline Derebe G.et al & 2014 & + & $9.60(6.80,12.40)$ & 8.06 \\
\hline Koye DN, Zeleke BM. & 2013 & + & $10.00(7.39,12.61)$ & 8.19 \\
\hline Wudineh F, Damtew B. & 2016 & $\rightarrow$ & $15.70(12.05,19.35)$ & 7.44 \\
\hline Abdula M. & 2015 & $\rightarrow-1$ & $7.70(3.12,12.28)$ & 6.72 \\
\hline Tigabu Z, Wasie B. & 2016 & $\leftarrow$ & $12.40(9.46,15.34)$ & 7.96 \\
\hline Shargie MB et al & 2011 & $\rightarrow$ & $6.80(2.26,11.34)$ & 6.75 \\
\hline Mirkuzie AH.et.al & 2010 & $\rightarrow$ & $11.80(9.69,13.91)$ & 8.49 \\
\hline Negash TG,Ehlers VJ. & 2016 & +1 & $6.00(3.62,8.38)$ & 8.33 \\
\hline \multirow{2}{*}{\multicolumn{2}{|c|}{$\begin{array}{l}\text { Overall (I-squared }=84.3 \%, \mathrm{p}<0.001 \text { ) } \\
\text { NOTE: Weights are from random effects analysis }\end{array}$}} & $\hat{v}$ & $11.41(9.11,13.71)$ & 100.00 \\
\hline & & & & \\
\hline & & 25 & 75 & \\
\hline
\end{tabular}

Fig. 3 Forest plot of the prevalence with corresponding $95 \% \mathrm{Cls}$ of the fourteen studies on MTCT of HIV. The midpoint and the length of each segment indicated prevalence and a $95 \% \mathrm{Cl}$ whereas the diamond shape showed the combined prevalence of all studies 


\begin{tabular}{|c|c|c|c|}
\hline \multicolumn{2}{|l|}{ Authori } & \multirow[t]{2}{*}{$\mathrm{P}(95 \% \mathrm{Cl})$} & \multirow[t]{2}{*}{$\begin{array}{l}\% \\
\text { Weight }\end{array}$} \\
\hline Amhara & 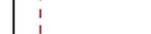 & & \\
\hline Moges AN et al & -1 & $5.90(3.26,8.54)$ & 8.16 \\
\hline Berhan Z et al & 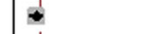 & $10.10(7.27,12.93)$ & 8.03 \\
\hline Koye DN, Zeleke BM & $\bullet$ & $10.00(7.39,12.61)$ & 8.19 \\
\hline Tigabu Z, Wasie B & $\$$ & $12.40(9.46,15.34)$ & 7.96 \\
\hline Subtotal (I-squared $=73.2 \%, p=0.011$ ) & 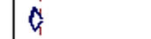 & $9.56(6.90,12.21)$ & 32.34 \\
\hline \multicolumn{4}{|l|}{ Addis Ababa } \\
\hline Amare $\mathrm{H}$ et al. & $1:$ & $32.10(24.84,39.36)$ & 4.80 \\
\hline Mirkuzie AH.et.al & $\rightarrow$ & $8.40(1.95,14.85)$ & 5.33 \\
\hline Shargie MB et al. & $\neq$ & $6.80(2.26,11.34)$ & 6.75 \\
\hline Mirkuzie AH.et.al & . & $11.80(9.69,13.91)$ & 8.49 \\
\hline Negash TG,Ehlers VJ. & -1 & $6.00(3.62,8.38)$ & 8.33 \\
\hline Subtotal (I-squared $=92.2 \%, p<0.001$ ) & $\phi$ & $12.34(6.50,18.19)$ & 33.69 \\
\hline \multicolumn{4}{|l|}{ Oromia } \\
\hline Kumela Ket al. & $\rightarrow$ & $15.50(10.21,20.79)$ & 6.17 \\
\hline Birlie B et al & 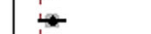 & $17.00(10.91,23.09)$ & 5.58 \\
\hline Derebe G.et al & $\bullet$ & $9.60(6.80,12.40)$ & 8.06 \\
\hline Abdula M & -1 & $7.70(3.12,12.28)$ & 6.72 \\
\hline Subtotal (I-squared $=68.3 \%, p=0.024)$ & 0 & $11.95(7.95,15.96)$ & 26.52 \\
\hline \multicolumn{4}{|l|}{ Dire Dawa } \\
\hline Wudineh F, Damtew B. & 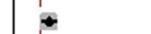 & $15.70(12.05,19.35)$ & 7.44 \\
\hline Subtotal $(1-$ squared $=. \%, p=)$. & $\hat{v}$ & $15.70(12.05,19.35)$ & 7.44 \\
\hline Overall $(\mathrm{I}$-squared $=84.3 \%, \mathrm{p}<0.001)$ & 0 & $11.41(9.11,13.71)$ & 100.00 \\
\hline \multicolumn{4}{|c|}{ NOTE: Weights are from random effects analysis } \\
\hline
\end{tabular}

Fig. 4 Forest plot of the prevalence with corresponding $95 \% \mathrm{Cls}$ of the subgroup analysis based on the regions, where the studies done. The midpoint and the length of each segment indicated prevalence and a $95 \% \mathrm{Cl}$ whereas the diamond shape showed the combined prevalence

during pregnancy $(\mathrm{AOR}=4.71,95 \% \mathrm{CI}=1.39-15.93)$ and after delivery ( $\mathrm{AOR}=4.46,95 \% \mathrm{CI}: 1.40-16.22)$ as compared with those who knew before getting pregnant [30]. The presence of mothers' illness during pregnancy $(\mathrm{AOR}=20.4,95 \% \mathrm{CI}: 3.1-25.7$ ) [26] and absence of maternal antenatal care visit $(\mathrm{AOR}=4.6$, 95\%CI: 1.17-17.99) [27] were also contributing factors to MTCT of HIV.

HIV exposed infants who were enrolled in the follow-up clinic lately (AOR $=2.89,95 \% \mathrm{CI}: 1.35,6.21$ ) were more likely to have HIV infection [22]. A mother who had cracked nipple and/or mastitis while lactating $(\mathrm{AOR}=13.05,95 \% \mathrm{CI}: 1.23-138.21)$ was also found a significant predictor [30].

Four studies [21, 22, 24, 25] showed a significant association between place of birth and MTCT of HIV. The pooled AOR of MTCT of HIV for infants born at home versus health institution was $3.2\left(95 \% \mathrm{CI}=1.2\right.$ to $5.2, \mathrm{I}^{2}$ $=0.0 \%, p=0.906$ ) (Fig. 7). Egger's regression test was showed a $p$-value of 0.055 .

Six studies $[20-22,25,26,30]$ showed a significant association between infant feeding practice and MTCT of HIV. The pooled AOR of MTCT of HIV in mixed feeding versus exclusive breastfeeding practice was 4.3 $\left(95 \% \mathrm{CI}=1.8\right.$ to $\left.6.7, \mathrm{I}^{2}=0.0 \%, p=0.860\right)$ (Fig. 7). Egger's regression test was showed a $p$-value of 0.085 .

\section{Clinical and drugs-related factors}

Delayed HIV diagnosis (AOR $=2.7,95 \% \mathrm{CI}=1.3,29.4$ ) [20], mothers being on late AIDS stage (AOR $=5.8 ; 95 \%$ CI: 1.6-16.5) [21], mothers with CD4 cell count $<200$ $(\mathrm{AOR}=7.65$, 95\%CI: $3.20-18.31)$, and 201-500 $(\mathrm{AOR}=$ 4. 07, 95\%CI: 1.90-8.71) cells/ $\mu$ l during lactation [30] were found more likely to transmit HIV to their child.

Three studies [21-23] showed a significant association between PMTCT utilization and MTCT of HIV. The pooled AOR of MTCT of HIV in infants whose mother couldn't get PMTCT intervention was $5.1(95 \% \mathrm{CI}=1.6$ to $8.6, \mathrm{I} 2=0.0 \%, p=0.837$ ) (Fig. 8). Egger's regression test was showed a $p$-value of 0.343 .

Five studies [20, 25-27, 30] showed a significant association between mothers on ART prophylaxis during pregnancy and/or breastfeeding and MTCT of HIV. The pooled AOR of MTCT of HIV in infants whose mothers didn't receive prophylaxis during pregnancy and/or breastfeeding was $6.1(95 \% \mathrm{CI}=2.3$ to $9.6, \mathrm{I} 2=42.5 \%, p$ 


\begin{tabular}{|c|c|c|c|}
\hline \multicolumn{2}{|l|}{ Author } & \multirow[t]{2}{*}{$\mathrm{P}(95 \% \mathrm{Cl})$} & \multirow[t]{2}{*}{$\begin{array}{l}\% \\
\text { Weight }\end{array}$} \\
\hline Cohort & $\begin{array}{l}1 \\
1 \\
1\end{array}$ & & \\
\hline Moges AN et al & 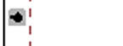 & $5.90(3.26,8.54)$ & 8.16 \\
\hline Amare $\mathrm{H}$ et al & $1 \rightarrow$ & $32.10(24.84,39.36)$ & 4.80 \\
\hline Kumela Ket al & $\rightarrow$ & $15.50(10.21,20.79)$ & 6.17 \\
\hline Birlie B et al & + & $17.00(10.91,23.09)$ & 5.58 \\
\hline Mirkuzie AH.et.al & $\rightarrow$ & $8.40(1.95,14.85)$ & 5.33 \\
\hline Derebe G.et al/2014 & $\star$ & $9.60(6.80,12.40)$ & 8.06 \\
\hline Koye DN, Zeleke BM & $\downarrow$ & $10.00(7.39,12.61)$ & 8.19 \\
\hline Wudineh F, Damtew B. & + & $15.70(12.05,19.35)$ & 7.44 \\
\hline Mirkuzie AH.et.al & i & $11.80(9.69,13.91)$ & 8.49 \\
\hline Subtotal $(I-$ squared $=87.2 \%, p<0.001)$ & $\hat{0}$ & $13.26(9.94,16.58)$ & 62.21 \\
\hline \multirow{2}{*}{\multicolumn{4}{|c|}{ cross-sectional }} \\
\hline & & & \\
\hline Berhan Z et al & 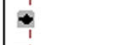 & $10.10(7.27,12.93)$ & 8.03 \\
\hline Abdula M & 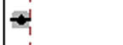 & $7.70(3.12,12.28)$ & 6.72 \\
\hline Tigabu Z, Wasie B & + & $12.40(9.46,15.34)$ & 7.96 \\
\hline Shargie MB et al & $\omega_{1}^{1}$ & $6.80(2.26,11.34)$ & 6.75 \\
\hline Negash TG,Ehlers VJ. & -1 & $6.00(3.62,8.38)$ & 8.33 \\
\hline Subtotal $(I-$ squared $=68.9 \%, p=0.012)$ & 0 & $8.71(6.09,11.34)$ & 37.79 \\
\hline Overall $(I-$ squared $=84.3 \%, \mathrm{p}<0.001)$ & 1 & $11.41(9.11,13.71)$ & 100.00 \\
\hline NOTE: Weights are from random effects & Aly,sis & & \\
\hline
\end{tabular}

Fig. 5 Forest plot of the prevalence with corresponding $95 \% \mathrm{Cls}$ of the study design. The midpoint and the length of each segment indicated prevalence and a $95 \% \mathrm{Cl}$ whereas the diamond shape showed the combined prevalence

$=0.138)$ (Fig. 8). Egger's regression test was showed a p-value of 0.204 .

Two studies [25, 27] showed a significant association between infants ART prophylaxis and MTCT of HIV. The pooled AOR of MTCT of HIV in infants didn't receive ARV prophylaxis was $5.8(95 \% \mathrm{CI}=1.5$ to 10.0 , I2 $=0.0 \%, p=0.936$ ) (Fig. 8).

\section{Discussion}

Our meta-analysis aimed to estimate the pooled prevalence of MTCT of HIV and its associated factors in Ethiopia. In this meta-analysis, the overall pooled prevalence rate of MTCT of HIV was $11.4 \%$. In addition, sociodemographic, natal, and clinical and drug-related factors were found to be the predictors of MTCT of HIV.

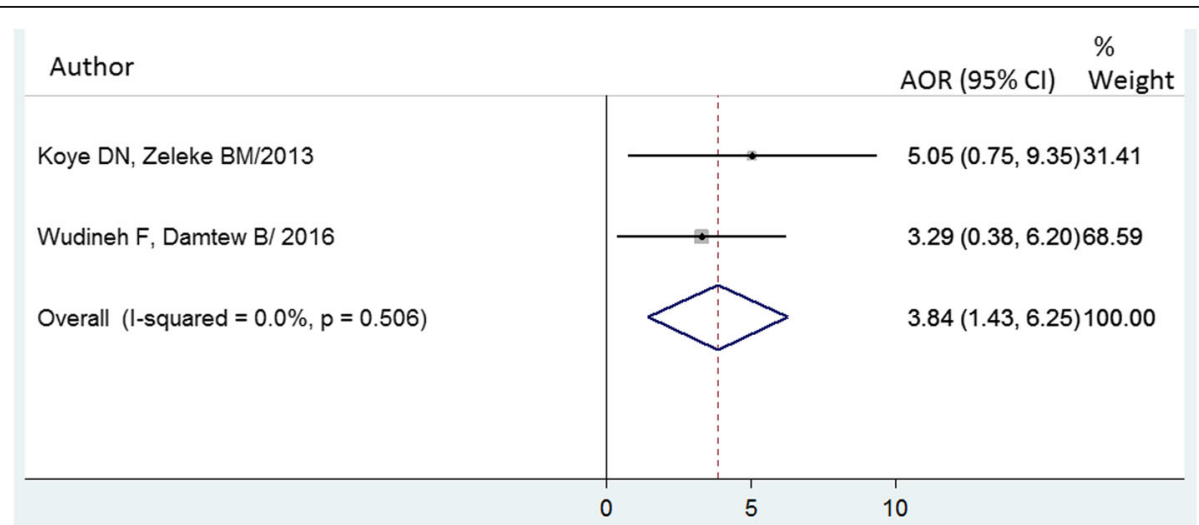

Fig. 6 Forest plot of the adjusted odds ratios with corresponding 95\% Cls of studies on the association of rural residence and MTCT of HIV. The midpoint and the length of each segment indicated an AOR and a $95 \% \mathrm{Cl}$; the arrow showed the widest $\mathrm{Cl}$; and the diamond shape showed the combined AOR of all studies 


\begin{tabular}{|c|c|c|}
\hline Author/year & $\operatorname{AOR}(95 \% \mathrm{CI})$ & $\begin{array}{l}\% \\
\text { Weight }\end{array}$ \\
\hline \multicolumn{3}{|l|}{ Mixed infant feeding } \\
\hline Burusie A, Deyessa N/2015 & $3.55(0.47,6.63)$ & 62.34 \\
\hline Wudineh F, Damtew B/ 2016 & $42.21(-60.82,145.24)$ & 0.06 \\
\hline Koye DN, Zeleke BM/2013 & $4.18(-0.52,8.88)$ & 26.77 \\
\hline Tadele T et al/2014 & $8.23(-7.88,24.34)$ & 2.28 \\
\hline Birlie B et al/2016 & $5.60(-14.30,25.50)$ & 1.49 \\
\hline Berhan Z et al/2014 & $8.80(-0.35,17.95)$ & 7.06 \\
\hline Overall (I-squared $=0.0 \%, p=0.860$ ) & $4.25(1.82,6.68)$ & 100.00 \\
\hline \multicolumn{3}{|l|}{ Home delivery } \\
\hline Wudineh F, Damtew B/ 2016 & $3.35(-0.05,6.75)$ & 35.69 \\
\hline Koye DN, Zeleke BM/2013 & $2.82(0.10,5.54)$ & 55.77 \\
\hline Birlie B et al/2016 & $8.10(-6.80,23.00)$ & 1.86 \\
\hline Asmamaw Y et al/2017 & $4.20(-3.66,12.06)$ & 6.68 \\
\hline Overall (I-squared $=0.0 \%, p=0.906)$ & $3.20(1.17,5.23)$ & 100.00 \\
\hline
\end{tabular}

Fig. 7 Forest plot of the adjusted odds ratios with corresponding 95\% Cls of studies on the association of home delivery and mixed infant feeding with MTCT of HIV. The midpoint and the length of each segment indicated an AOR and a 95\% Cl; the arrow showed widest $\mathrm{Cl}$; and the diamond shape showed the combined AOR of all studies for each variable

The prevalence of MTCT of HIV in the current study was higher than 2013 United Nations Program on HIV/ AIDS reports in South Africa (6\%) and in Botswana (2\%) [41]. Low maternal adherence to antenatal care utilization, extensive home delivery, less availability and accessibility of PMTCT interventions and HIV counseling in remote areas, inconsistent availability of infrastructures like roads, light and water and prevailing pre-lacteal feeding habit might cause the higher rate of MTCT of HIV in Ethiopia. Low level of knowledge and awareness of mothers about MTCT of HIV might also attribute to high HIV infection rate among infants in Ethiopia [42, 43]. Moreover, MTCT of HIV has been eliminated in some countries, like Cuba, Belarus, Armenia, and Thailand [44]. This might be due to, in these countries, minimized of the pregnant women practiced unprotected sex, women with HIV in those countries didn't breastfeed their babies, availability of best suited safe and healthy alternative baby formula, good attitudes and perceptions to use HIV drugs during pregnancy, high level of early HIV test before getting pregnant and/or during pregnancy, and persistence implementation of PMTCT after the infants delivered safely.

Although the current finding showed the high burden, it is lower than 2013 UNAIDS reports in Burkina Faso (22\%) and in Ethiopia (25\%) [41]. The possible reasons for such discrepancy might be related to year of the study, and an emerging of new strategies and improvement on HIV prevention and control activities.

The subgroup analysis revealed that there was a significant variation among regions. Infants born from HIV-positive mothers in Amhara region had lower rates of MTCT of HIV compared to Addis Ababa and Oromia regions. However, this finding was inconsistent with the 2016 Ethiopia Demographic Health Survey (EDHS) reports in Addis Ababa and Amhara region [16]. This discrepancy might be due to the fact that there might be the change in the epidemiological transitions of diseases, on and off interventions as per the prevailing HIV cases, the difference in HIV-test coverage, and the difference of awareness to HIV.

According to this study, infants from the rural residence were nearly four times more likely to acquire HIV infection from their mothers. This could be due to living in rural area of Ethiopia, low knowledge to MTCT of HIV, the high proportion of mothers unaware of their HIV status, lack of clinic-based education and counseling [45], lower level of education, belonging to lower wealth, and not exposed to mass media [46].

In this study, infants delivered at home were nearly three times more likely to get HIV infection compared to infants delivered at health institutions. This finding was in agreement with a study conducted in Nigeria [47] and Zimbabwe [48]. This could be due to home delivery 


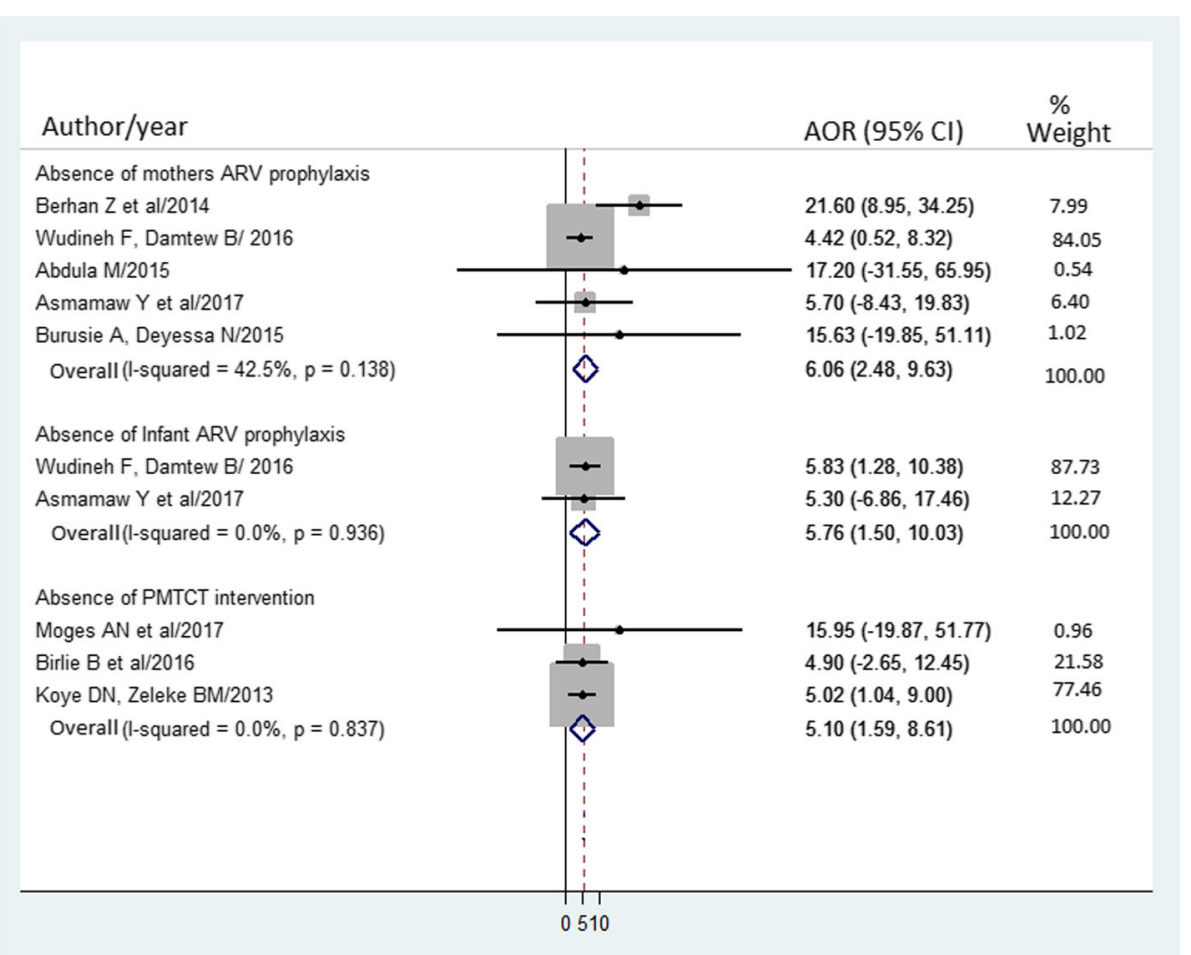

Fig. 8 Forest plot of the adjusted odds ratios with corresponding 95\% Cls of studies on the association of absence of mother ARV prophylaxis, absence of infant ARV prophylaxis, and absence of PMTCT intervention with MTCT of HIV. The midpoint and the length of each segment indicated an AOR and a 95\% Cl; the arrow showed widest $\mathrm{Cl}$; and the diamond shape showed the combined AOR of all studies for each variable

lack implementation of HIV prevention strategies as it does in the health institution. The $90 \%$ of HIV-infection among infants born from seropositive mothers is higher during labor and delivery [5], particularly in the absence of integrated HIV services. The previous study [49] in Africa showed infants who delivered at home were more prone to many harmful traditional practices that promote HIV-infection rate, such as cord-cutting by shared razor, placental blood contamination, uvulectomy, unplanned circumcision, pre-lacteal feeding, and breastfeeding from unexamined nipples.

This study also showed that HIV-exposed infants who didn't take ARV prophylaxis and whose mothers didn't receive prophylaxis during pregnancy and/or breastfeeding were nearly six times more likely to get HIV-infection. This finding was in line with a study conducted in Cote'devore [50], South Africa, and sub-Saharan Africa $[51,52]$. There is also evidence that showed not initiating ARV prophylaxis to the infant is a risk factor for MTCT of HIV [53, 54]. This is due to the fact that without ARV drugs a potential effect of HIV transcription, replication, and fusion increased in the human body [55]. Besides, those infants whose mother couldn't get PMTCT intervention were 5 times more likely to have HIV infection. This finding was in agreement with studies done in Kenya $[56,57]$. PMTCT strategies are considering prevention of
HIV infection among women, prevention of unwanted pregnancy, antenatal protection of fetus, test and counseling of pregnant women, ARV prophylaxis, and treatment of pregnant women. Therefore, MTCT of HIV could highly observable among those mothers lacked PMTCT interventions.

Mixed infant feeding practice also identified as a key predictor of high rate of MTCT of HIV; infants who received mixed feeding were seven times more likely to acquire HIV infection compared to those exclusively breastfed. This finding agreed with studies in South Africa [58] and Zimbabwe [59]. Mixed feeding practices may cause laceration of gastrointestinal mucosa which would create a favorable entry of the virus into the bloodstream.

MTCT continues to be a devastating clinical and/or public health burden in Ethiopia. Adequate emphasis has not been given on this pandemic which might lead to increased hospitalizations, cost of healthcare services and reduction of the overall economic structure of the nation. It could be reduced if all women delivered at health institutions. To achieve the WHO's end AIDS strategy [11], Ethiopia planned to create "HIV-free generation by the year 2020" [13] and implementing the health policy that focused on PMTCT and other infectious diseases. However, the burden of MTCT of HIV remains high in the Ethiopian population. Thus, the 
finding of this study would be important to develop further HIV control interventions and may have a significant impact on health service resource utilization. It also contributes to the growing need for undertaking ART. It will have direct or indirect importance in providing information to the Joint United Nations Programme on HIV/AIDS and partners, 90-90-90 targets; $90 \%$ of all HIV-positive persons identified, provide antiretroviral therapy (ART) for $90 \%$ of those diagnosed, and achieve viral suppression for $90 \%$ of those treated by 2020 .

\section{Strength and limitation}

This study as it is the first systematic review and meta-analysis that provided the national prevalence estimate on MTCT of HIV. In addition, the effects of three key predictors of MTCT of HIV were estimated. On the other hand, given the limited number of studies, the result may not represent the national figure. Furthermore, the time-trend analysis was not conducted because studies were not available in all the year.

\section{Conclusion}

The MTCT rate of HIV was high. Urban residence, home delivery, not taking antiretroviral prophylaxis, the absence of PMTCT intervention, and mixed infant feeding practices were significant predictors of MTCT in Ethiopia.

\section{Additional files}

Additional file 1: Research check list. (DOC $63 \mathrm{~kb}$ )

Additional file 2: Search strategy. (DOCX $16 \mathrm{~kb}$ )

\section{Abbreviations}

AIDS: Acquired Immunodeficiency Syndrome; ARV: Antiretroviral; Cl: Confidence Interval; HIV: Human Immunodeficiency Virus; MTCT: Motherto-Child Transmission; OR: Odds Ratio; PMTCT: Prevention of Mother to Child Transmission

\section{Funding}

There is no received grant from any fund agency.

\section{Availability of data and materials}

All data generated or analyzed during this study are included in this published article and its Additional files.

\section{Authors' contributions}

AE conceived and designed the study. AE and TDH established the search strategy. AE, TDH, AD and SE wrote the review. All the authors read the manuscript before they have given the final approval for publication.

\section{Ethics approval and consent to participate}

Not applicable because no primary data were collected.

\section{Consent for publication}

Not applicable

\section{Competing interests}

The authors declare that they have no competing interests.

\section{Publisher's Note}

Springer Nature remains neutral with regard to jurisdictional claims in published maps and institutional affiliations.

\section{Author details}

'Department of Pediatrics and Child Health Nursing, School of Nursing, College of Medicine and Health Sciences, University of Gondar, P.O.BOX: 196 Gondar, Ethiopia. ${ }^{2}$ Department of Medical Microbiology, School of Biomedical and Laboratory Sciences, College of Medicine and Health Sciences, University of Gondar, Gondar, Ethiopia. ${ }^{3}$ University of Groningen, University Medical Center Groningen, University Center for Psychiatry, Rob Giel Research Centre, Groningen, The Netherlands. ${ }^{4}$ University Medical Center Groningen, Department of Epidemiology, University of Groningen, Groningen, The Netherlands.

Received: 26 January 2018 Accepted: 11 June 2018

Published online: 22 June 2018

\section{References}

1. Cohen MS, Hellmann N, Levy JA, DeCock K, Lange J. The spread, treatment, and prevention of HIV-1: evolution of a global pandemic. J Clin Invest. 2008; 118(4):1244

2. UNAIDS. Global HIV statistics: Fact sheet. 2017.

3. World Health Organization. On the fast-track to an AIDS-free generation. Geneva: World Health Organization; 2016.

4. Friedland GH, Klein RS. Transmission of the human immunodeficiency virus. N Engl J Med. 1987;317(18):1125-35.

5. World Health Organization. PMTCT strategic vision 2010-2015: preventing mother-to-child transmission of HIV to reach the UNGASS and Millennium Development Goals; 2010. p. 9241599030.

6. Car LT, Van Velthoven MH, Brusamento S, Elmoniry H, Car J, Majeed A, et al. Integrating prevention of mother-to-child HIV transmission programs to improve uptake: a systematic review. PLoS One. 2012;7(4):e35268.

7. World Health Organization \& Unicef. Global monitoring framework and strategy for the global plan towards the elimination of new HIV infections among children by 2015 and keeping their mothers alive (EMTCT), April 2012. 2012.

8. Drake AL, Wagner A, Richardson B, John-Stewart G. Incident HIV during pregnancy and postpartum and risk of mother-to-child HIV transmission: a systematic review and meta-analysis. PLoS Med. 2014;11(2):e1001608.

9. John GC, Kreiss J. Mother-to-child transmission of human immunodeficiency virus type 1. Epidemiol Rev. 1996;18(2):149.

10. Adetokunboh OO, Oluwasanu M. Eliminating mother-to-child transmission of the human immunodeficiency virus in sub-Saharan Africa: the journey so far and what remains to be done. Journal of infection and public health. 2016;9(4):396-407.

11. KAZANJIAN P. UNAIDS 90-90-90 campaign to end the AIDS epidemic in historic perspective. The Milbank Quarterly. 2017:95(2):408-39.

12. Joint United Nations Programme on HIV/AIDS (UNAIDS). Progress report on the global plan towards the elimination of new HIV infections among children by 2015 and keeping their mothers alive. Geneva: UNAIDS; 2014.

13. Ethiopia Federal Ministry of Health (EFMOH) and HAPCO. Federal HIV/AIDS Prevention and Control Office. Guidelines for Prevention of Mother-to-Child Transmission of HIV In Ethiopia. EFMOH; 2007.

14. World Health Organization. Consolidated guidelines on the use of antiretroviral drugs for treating and preventing HIV infection: recommendations for a public health approach. Geneva: World Health Organization; 2016.

15. lliff PJ, Piwoz EG, Tavengwa NV, Zunguza CD, Marinda ET, Nathoo KJ, et al. Early exclusive breastfeeding reduces the risk of postnatal HIV-1 transmission and increases HIV-free survival. AIDS. 2005;19(7):699-708.

16. Central Statistical Agency (CSA) [Ethiopia] and ICF. Ethiopia Demographic and Health Survey 2016, vol. 2016. Addis Ababa, Ethiopia, and Rockville, Maryland, USA: CSA and ICF.

17. Health Mo. Health Sector Development Programme IV. Annual performance report. Addis Ababa: Government of Ethiopia; 2010.

18. Abdula M, Tilahun Z, Workneh S. Assessment of effectiveness of prevention of mother to child transmission of human immunodeficiency virus in Asella hospital, Ethiopia. Eur J Clin Pharm. 2017;19(3):198-206.

19. Amare $H$, Weldesenbet $Z, G / T$ sadik $A$, Ayalew $E$, IAragaw $R$, Hassen $F$, et al. Prevalence and risk factors of HIV infection among infants, born from HIV 
seropositive mothers, tested by DNA-PCR at Yekatit 12 Hospital, Addis Ababa, Ethiopia. Int J Pharma Sci Res (IJPSR). 2014.

20. Berhan Z, Abebe F, Gedefaw M, Tesfa M, Assefa M, Tafere Y. Risk of HIV and associated factors among infants born to HIV positive women in Amhara region, Ethiopia: a facility based retrospective study. BMC research notes. 2014;7(1):876.

21. Birlie B, Diriba T, Sisay K, Gurmessa A, Seyoum D. Mother to child HIV transmission and its predictors among HIV-exposed infants: a retrospective follow-up study in Southwest Ethiopia. J AIDS Clin Res. 2016;7(605):2.

22. Koye DN, Zeleke BM. Mother-to-child transmission of HIV and its predictors among HIV-exposed infants at a PMTCT clinic in Northwest Ethiopia. BMC Public Health. 2013;13(1):398.

23. Moges NA, Kassa GM, Boneya DJ. Rate of HIV transmission and associated factors among HIV-exposed infants in selected health facilities of east and west Gojjam zones, Northwest Ethiopia; retrospective cohort study. BMC Infect Dis. 2017;17(1):475.

24. Tigabu Z, Wasie B. Outcomes and linkage to chronic care of HIV exposed infants among health centers and hospitals in Amhara region, Ethiopia: implications to prevention of mother-to child transmission of HIV program: a cross sectional study. Pan Afr Med J. 2016;24(1)

25. Wudineh F, Damtew B. Mother-to-child transmission of HIV infection and its determinants among exposed infants on care and follow-up in Dire Dawa City, eastern Ethiopia. AIDS Res Treatment 2016;2016:1-6.

26. Tadele T, Tamiso A, Tadele T. Incidences and predictors of HIV positivity among infants who born from HIV positive mother who have follow up at two hospitals of southern Ethiopia, 2014. Sci J Public Health. 2014;2(5):431-9.

27. Asmamaw $Y$, Mengistu D, Aragew Z. Mother to child HIV transmission and associated factors among HIV exposed infants at govermental health facilities, Dessie town, Ethiopia. [research article]. In press 2017.

28. Girma M. Effectiveness of prevention of mother-to-child transmission (PMTCT) procedures in pregnant HIV infected women and their exposed infants at seven health centers in Addis Ababa, Ethiopia; University of Munich (LMU); 2016

29. Shargie MB, Eek F, Abaychew A. Prophylactic treatment uptake and compliance with recommended follow up among HIV exposed infants: a retrospective study in Addis Ababa, Ethiopia. BMC research notes. 2011:4(1):563.

30. Burusie ADN. Determinants of mother to child HIV transmission (HIV MTCT); a case control study in Assela, Adama and Bishoftu hospitals, Oromia regional state. Ethiopia Cell Dev Biol. 2015;4:1000152. https://doi.org/10. 4172/2168-9296.1000152

31. Mirkuzie AH, Hinderaker SG, Mørkve O. Promising outcomes of a national programme for the prevention of mother-to-child HIV transmission in Addis Ababa: a retrospective study. BMC Health Serv Res. 2010;10(1):267.

32. Derebe G, Biadgilign S, Trivelli M, Hundessa G, Robi ZD, Gebre-Mariam M, et al. Determinant and outcome of early diagnosis of HIV infection among HIV-exposed infants in Southwest Ethiopia. BMC research notes. 2014;7(1):309.

33. Mirkuzie AH, Hinderaker SG, Sisay MM, Moland KM, Mørkve O. Current status of medication adherence and infant follow up in the prevention of mother to child HIV transmission programme in Addis Ababa: a cohort study. J Int AIDS Soc. 2011;14(1):50.

34. Kumela K, Amenu D, Chelkeba L. Comparison of anti-retroviral therapy treatment strategies in prevention of mother-to-child transmission in a teaching hospital in Ethiopia. Pharm Pract. 2015;13(2)

35. Negash TG, Ehlers VJ. An assessment of the outcomes of prevention of mother-to-child transmission of HIV services in Addis Ababa. Ethiopia Curationis. 2016;39(1):1-9.

36. Liberati A, Altman DG, Tetzlaff J, Mulrow C, Gøtzsche PC, loannidis JP, et al The PRISMA statement for reporting systematic reviews and meta-analyses of studies that evaluate health care interventions: explanation and elaboration. PLoS Med. 2009;6(7):e1000100.

37. Joanna Briggs Institute. Critical Appraisal Tools [Internet]. 2005.

38. DerSimonian R, Kacker R. Random-effects model for meta-analysis of clinical trials: an update. Contemporary clinical trials. 2007;28(2):105-14.

39. Higgins JP, Thompson SG, Deeks JJ, Altman DG. Measuring inconsistency in meta-analyses. BMJ: British Medical Journal. 2003;327(7414):557.

40. Peters JL, Sutton AJ, Jones DR, Abrams KR, Rushton L. Comparison of two methods to detect publication bias in meta-analysis. JAMA. 2006;295(6):676-80.

41. Hill A, Dauncey T, Levi J, Heath K, Casas CP. Higher risks of mother-to-child HIV transmission in countries with lower HIV prevalence: UNAIDS 2013 results for 32 countries with generalised epidemics. J Virus Erad. 2015;1 (4):257.
42. Abtew S, Awoke W, Asrat A. Knowledge of pregnant women on mother-tochild transmission of HIV, its prevention, and associated factors in Assosa town, Northwest Ethiopia. HIV/AIDS (Auckl). 2016;8:101.

43. Sahlu I, Howe CJ, Clark MA, Marshall BD. HIV status, knowledge of motherto-child transmission of HIV and antenatal care use among Ethiopian women. J Epidemiol Glob Health. 2014;4(3):177-84.

44. Taylor M, Newman L, Ishikawa N, Laverty M, Hayashi C, Ghidinelli M, et al. Elimination of mother-to-child transmission of HIV and syphilis (EMTCT): process, progress, and program integration. PLoS Med. 2017;14(6):e1002329.

45. Abajobir AA, Zeleke A. Knowledge, attitude, practice and factors associated with prevention of mother-to-child transmission of HIV/AIDS among pregnant mothers attending antenatal clinic in Hawassa referral hospital, South Ethiopia. Journal of AIDS and. Clin Res. 2013;4(6):2-7.

46. Luba TR, Feng Z, Gebremedhin SA, Erena AN, Nasser AM, Bishwajit G, et al. Knowledge about mother-to-child transmission of HIV its prevention and associated factors among Ethiopian women. J Global Health. 2017;7(2):3-6.

47. Ogunbosi BO, Oladokun RE, Brown BJ, Osinusi Kl. Prevalence and clinical pattern of paediatric HIV infection at the university college hospital, Ibadan, Nigeria: a prospective cross-sectional study. Ital J Pediatr. 2011;37(1):29.

48. Kurewa E, Kandawasvika G, Mhlanga F, Munjoma M, Mapingure M, Chandiwana $P$, et al. Realities and challenges of a five year follow up of mother and child pairs on a PMTCT program in Zimbabwe. The open AIDS journal. 2011;5:51

49. Hrdy DB. Cultural practices contributing to the transmission of human immunodeficiency virus in Africa. Rev Infect Dis. 1987;9(6):1109-19.

50. Dabis F, Bequet L, Ekouevi DK, Viho I, Rouet F, Horo A, et al. Field efficacy of zidovudine, lamivudine and single-dose nevirapine to prevent peripartum HIV transmission. AIDS (London, England). 2005;19(3):309.

51. Hoffman R, Black V, Technau K, van der Merwe KJ, Currier J, Coovadia A, et al. Effects of highly active antiretroviral therapy duration and regimen on risk for mother-to-child transmission of HIV in Johannesburg, South Africa. J Acquir Immune Defic Syndr. 2010;54(1):35

52. Ciaranello AL, Seage IIIGR, Freedberg KA, Weinstein MC, Lockman S, Walensky RP. Antiretroviral drugs for preventing mother-to-child transmission of HIV in sub-Saharan Africa: balancing efficacy and infant toxicity. AIDS (London, England). 2008;22(17):2359.

53. Taha TE, Kumwenda NI, Gibbons A, Broadhead RL, Fiscus S, Lema V, et al. Short postexposure prophylaxis in newborn babies to reduce mother-tochild transmission of HIV-1: NVAZ randomised clinical trial. Lancet. 2003; 362(9391):1171-7.

54. Volmink J, Siegfried N, van der Merwe L, Brocklehurst P. Antiretrovirals for reducing the risk of mother-to-child transmission of HIV infection. Cochrane Database Syst Rev. 2007;1

55. Braunwald E, Fauci A, Kasper D, Hauser S, Longo D, Jameson L. Harrison's principles of internal medicine. NY: 11th: McGraw-hill book company; 2001.

56. Okoko NA, Owuor KO, Kulzer JL, Owino GO, Ogolla IA, Wandera RW, et al. Factors associated with mother to child transmission of HIV despite overall low transmission rates in HIV-exposed infants in rural Kenya. Int J STD AIDS. 2017;28(12):1215-23.

57. Nduati EW, Hassan AS, Knight MG, Muema DM, Jahangir MN, Mwaringa SL, et al. Outcomes of prevention of mother to child transmission of the human immunodeficiency virus-1 in rural Kenya-a cohort study. BMC Public Health. 2015;15(1):1008.

58. Coovadia H, Rollins N, Bland R, Little K, Coutsoudis A, Bennish M, et al. Lancet: mother-to-child transmission of HIV-1 infection during exclusive breastfeeding in the first 6 months of life: an intervention cohort study. Breastfeeding Review. 2008;16(1):30-2.

59. Ngwende S, Gombe NT, Midzi S, Tshimanga M, Shambira G, Chadambuka A Factors associated with HIV infection among children born to mothers on the prevention of mother to child transmission programme at Chitungwiza hospital, Zimbabwe. 2008 BMC public health. 2013;13(1):1181. 